\title{
Comparison of shear bond strength of four different flowable composites and orthodontic resin with and without prior adhesive primer application - an in vitro study
}

\section{Brief resume of the intended study}

Need for the study: The most popular bonding method in orthodontics has been based on the acid etch technique which was introduced in 1955 by Buonocore, ${ }^{1}$ and modified for orthodontic purposes in 1960s by Newman. ${ }^{2}$ The important step in this technique to precondition the enamel surface with a $37 \%$ orthophosphoric acid solution or gel for approximately 30 seconds and dissolve the minerals of the enamel for the direct bonding of orthodontic brackets was reported. ${ }^{2}$ Traditional orthodontic bracket bonding systems required the use of a 3 -step procedure involving 3 separate agents- an enamel conditioner, a priming agent, and an adhesive resin. ${ }^{3}$ Development of flowable composites used for bonding of orthodontic brackets onto tooth surfaces has greatly improved with the qualities that have been of most interest including bond strength, adequate working time. It reduces the number of steps during bonding, and the potential errors related to contamination during bonding. ${ }^{4}$ Eliminating the application of primer would be advantageous for orthodontic bracket bonding which can reduce the number of steps.

However, although eliminating the placement of a bonding agent after a separate etching process would result in a comparable number of steps to using a one-step etch/bond agent, there would be a cost advantage. ${ }^{5}$ Flowable composites also show two desirable clinical handling characteristics that have not existed for composites until very recently: 1 . Non stickiness, so that material could be packed or condensed, and 2. Fluid injectability. ${ }^{6}$ There are still few studies available on the bonding characteristics of flowable composites and the effect of these materials on the enamel surfaces during debonding. ${ }^{7-10}$ Keeping in mind all the above mentioned points, this study will be aimed to compare the shear bond strength of the brackets bonded with conventional orthodontic resin and four different flowable composites with and without prior adhesive primer application.

\section{Review of literature}

A study was conducted to evaluate the shear bond strength \& site of bond failure for two visible light cured composites \& one resin modified glass ionomer cement. It was concluded that if bond strength was the primary consideration for choosing an adhesive, then composite should be utilized. ${ }^{11}$ An in vitro study evaluated the effect of repeated bonding on the shear bond strength of orthodontic brackets using a composite resin orthodontic adhesive. In conclusion, the authors stated that rebonded brackets had significantly lower \& inconsistent shear bond strength. ${ }^{12}$

A study was done to compare the shear bond strength of two light cured hydrophilic bonding systems with a hydrophobic bonding system under different enamel surface condition. It concluded that non-contaminated enamel surfaces had the highest bond strengths
Volume 9 Issue 6 - 2018

Harshad Ghorpade

Department of Orthodontics, Bahrain

Correspondence: Harshad Ghorpade, Department of Orthodontics, Bahrain, Email hgharpade@gmail.com

Received: August 30, 2017 | Published: November 23, 2018

for both the hydrophilic and hydrophobic materials. When using a hydrophobic primer, if the etched surface is contaminated with saliva before primer application, it may be necessary to re-etch before proceeding with the bonding procedure. If the contamination occurred after the primer had been placed and cured, simple drying and reapplication of the primer may be necessary. The hydrophilic primers also showed improved bond strength with reapplication of primer after saliva contamination. ${ }^{13}$ A study was conducted to determine the shear bond strength values of different flowable composites without primer application in comparison with a conventional orthodontic adhesive with primer application. The study concluded that flowable composite with no intermediate bonding resin could be conveniently applied for orthodontic bracket bonding. ${ }^{10}$ An in vitro study was conducted to compare the shear bond strength of organically modified ceramic matrix - ORMOCER to that of traditional composite. It was concluded that Ormocer could potentially have orthodontic applications if available in a more flowable form. ${ }^{14} \mathrm{~A}$ study was done to determine the shear bond strength value of a dental flowable composite - Dentiflow \& the mode of its bond failure after debonding. It was concluded that Dentiflow had the same shear bond strength as traditional composite resins \& similar bond failure patterns. ${ }^{15} \mathrm{An}$ in vitro study was conducted to compare the shear bond strength of a nano- hybrid restorative composite with that of a traditional adhesive material when used for bonding orthodontic brackets. It was concluded that nano- filled composite could potentially be used to bond orthodontic brackets to the tooth. ${ }^{16}$

\section{Objectives of the study}

1. To evaluate the shear bond strength of a conventional composite and four different flowable composites with prior adhesive primer application used for bracket bonding.

2. To evaluate the shear bond strength of a conventional composite and four different flowable composites without prior adhesive primer application used for bracket bonding.

3. To compare the differences in shear bond strength of different composites.

4. To determine and compare the amount of adhesive remnant on each tooth after debonding brackets for different composites. 


\section{Material \& methods}

\section{Source of data}

Total 5 different composite materials obtained from respective manufacturer.

\section{Methods of collection of data}

Extracted 100 premolar will be collected and study conducted in Goa dental college \& Hospital, Bambolim Goa, India.

Type of study: Prospective Study.

\section{Materials used}

A. Four flowable composites namely,

1. Transbond supreme LV, 3M UNITEK (manufacturer)

2. G-aenial Universal flow, GC India Ltd. (manufacturer)

3. Admira flow, Voco (manufacturer)

4. Tetric Flow, Ivoclar-Vivadent (manufacturer)

B. One conventional composite

1. Transbond XT, 3M UNITEK (manufacturer)

C. 100 stainless steel metal premolar brackets- Gemini metal brackets $.022(0,56 \mathrm{~mm})$ MBT Rx.

D. Etchant: $3 \mathrm{M}$ ESPE

E. 3M ESPE ELISPAR 2500 Light Cure Unit

F. Transbond XT primer, 3M UNITEK

G. A total 100 sound-extracted human premolars stored in a $0.5 \%$ chloramine T solution.

\section{Inclusion criteria}

1. Teeth with intact buccal enamel.

2. Teeth extracted for orthodontic treatment.

3. Teeth not subjected to any pretreatment chemical agents.

\section{Exclusion criteria}

1. Teeth having surface cracks from extraction forceps.

2. Teeth treated with chemical agents.

3. Teeth having caries or enamel defects and delamination of the enamel.

\section{Methodology}

A total of 100 sound-extracted human premolars will be stored in $0.5 \%$ chloramine $\mathrm{T}$ solution after extraction. The premolars will be mounted in a self-cure acrylic block. The buccal crown surface of each premolar will be rinsed and dried after a 15 -second polish with fluoride free pumice slurry. 100 teeth will be divided into 5 experimental groups with 20 teeth in each experimental group $(\mathrm{N}=20)$ and 4 experimental groups $(\mathrm{N}=20 \mathrm{X} 4=80)$ of flowable composites (Transbond supreme LV, 3M unitek; G-aenial Universal flow, GC India Ltd; Admira flow, Voco; Tetric Flow, Ivoclar-Vivadent) will be used to test shear bond strength and one experimental group ( $\mathrm{N}=20)$ of conventional composite (Transbond XT, 3M unitek) will be used to test shear bond strength. For all the experimental groups, the buccal enamel surface will be etched with $37 \%$ phosphoric acid gel (Etch) for 30 seconds, rinsed for 15 seconds, and dried with oil-free and moisture-free air for 20 seconds until the enamel will become faintly white. After acid etching, for each experimental group, half of the specimens $(\mathrm{N}=10)$ a thin layer of Transbond XT primer will be applied and light cured according to manufacturer's instructions. Primer will not be applied for another half of the specimen $(\mathrm{N}=10)$ of each experimental group. Composites will be applied to the bracket base, and the bracket will be positioned on the tooth and pressed firmly with a Hollenback carver to expel the excess adhesive. Then, the composite will be light cured for 20 seconds from the occlusal edge and 20 seconds from the gingival bracket edge.

The bracketed teeth will then be immersed in sealed containers of deionized water and placed in an incubator at $37^{\circ} \mathrm{C}$ for 72 hours to permit adequate water absorption and equilibration, and then the tests for examining the shear bond strength will be performed. The specimens will be secured in a jig attached to the base plate of a universal testing machine. A chisel-edge plunger will be mounted in the movable crosshead of the testing machine and positioned so that the leading edge will be aimed at the enamel-composite interface before being brought into contact. A crosshead speed of $0.5 \mathrm{~mm} / \mathrm{min}$ will be used. After debonding, each specimen will be examined under a stereoscopic zoom microscope (10X) to identify the location of the bond failure. The residual composite remaining on the premolar will be assessed by using the remnant index (ARI), where each specimen will be scored according to the amount of material remaining on the enamel surface.

\section{Statistical analysis}

Descriptive statistics including means (MPa) and standard deviations (SD) will be calculated for the shear bond strength analysis. A two way analysis of variance (ANOVA) and Student-Newman-Keuls multiple comparison tests will be used to determine the statistical significance of any difference in mean shear bond strengths among the 10 groups. The ARI will be analysed for percentage and frequency of fracture type, and a chi-square test will be used as the statistical test. Significance for all statistical tests will be predetermined at $\mathrm{P}<0.05$.

\section{Does the study require any investigations or interventions to be conducted in patients or other humans?}

No.

\section{Conclusion}

A study was conducted to determine the shear bond strength values of different flowable composites without primer application in comparison with a conventional orthodontic adhesive with primer application. The study concluded that flowable composite with no intermediate bonding resin could be conveniently applied for orthodontic bracket bonding. ${ }^{10}$ It was also concluded that if bond strength was the primary consideration for choosing an adhesive, then composite should be utilized. ${ }^{11}$

\section{Acknowledgments}

None.

\section{Conflicts of interest}

The author declares that there is no conflicts of interest. 


\section{References}

1. Buonocore MG. A simple method of increasing the adhesion of acrylic filling materials to enamel surfaces. $J$ Dent Res. 1955;34(6):849-853.

2. Newman GV. Bonding plastic orthodontic attachments to tooth enamel. $J$ NJ Dent Soc. 1964;35:346-358.

3. Bishara SE, Gordan VV, Von Wald L, et al. Effect of an acidic primer on shear bond strength of orthodontic brackets. Am J Orthod Dentofacial Orthop. 1998;114(3):243-247.

4. Elaut J, Asscherickx K, Vannet BV, et al. Flowable composites for bonding lingual retainers. J Clin Orthod. 2002;36(10):597-598.

5. Albaladejo A, Montero J, Diego RGD, et al. Effect of adhesive application prior to bracket bonding with flowable composites. Angle Orthod. 2011;81(4):716-720.

6. Tecco S, Traini T, Caputi S, et al. A new one-step dental flowable composite for orthodontic use: an in vitro bond strength study. Angle Orthod. 2005;75(4):672-677.

7. Lalani N, Foley TF, Voth R, Banting D, Mamandras AH. Polymerization with the argon laser: curing time and shear bond strength. Angle Orthod. 1999;69:525-534.

8. Meehan PM, Foley TF, Mamandras AH. A comparison of the shear bond strengths of two glass ionomer cements. Am J Orthod Dentofacial Orthop. 1999;115(2):125-132.
9. Ozel E, Korkmaz Y, Attar N, et al. Effect of one-step polishing systems on surface roughness of different flowable restorative materials. Dent Mater J. 2008;27(6):755-764.

10. Ryou DB, Park HS, Kim KH, et al. Use of flowable composites for orthodontic bracket bonding. Angle Orthod. 2008;78(6):1105-1109.

11. Owens SE, Miller BH. A comparison of shear bond strengths of three visible light cured orthodontic adhesives. Angle Orthod. 2000;70(5):352-356

12. Bishara SE, Von Wald L, Laffoon JF, et al. The effect of repeated bonding on the shear bond strength of a composite resin orthodontic adhesive. Angle Orthod. 2000;70(6):435-441.

13. Webster MJ, Nanda RS, Duncanson MG, et al. The effect of saliva on shear bond strengths of hydrophilic bonding systems. Am J Orthod Dentofacial Orthop. 2001;119(1):54-58.

14. Ajlouni R, Bishara SE, Soliman MM, et al. The use of ormocer as an alternative material for bonding orthodontic brackets. Angle Orthod. 2005;75(1):106-108.

15. D'Attilio M, Traini T, Di Iorio D. Shear bond strength, bond Failure and scanning electron microscopy analysis of a new flowable composite for orthodontic use. Angle Orthod. 2005;75(1):410-415.

16. Bishara SE, Ajlouni R, Soliman MM, et al. Evaluation of a new nanofilled restorative material for bonding orthodontic brackets. World $J$ Orthod. 2007;8(1):8-12. 